University of Nebraska - Lincoln

DigitalCommons@University of Nebraska - Lincoln

Toxicity Comparison Of Eight Repellents Against Four Species Of Female Mosquitoes

Julia W. Pridgeon

USDA-ARS

Ulrich R. Bernier

University of Florida, ubernier@gainesville.usda.ufl.edu

James J. Becnel

USDA-ARS, James.Becnel@ars.usda.gov

Follow this and additional works at: https://digitalcommons.unl.edu/usdaarsfacpub

Part of the Agricultural Science Commons

Pridgeon, Julia W.; Bernier, Ulrich R.; and Becnel, James J., "Toxicity Comparison Of Eight Repellents Against Four Species Of Female Mosquitoes" (2009). Publications from USDA-ARS / UNL Faculty. 953. https://digitalcommons.unl.edu/usdaarsfacpub/953

This Article is brought to you for free and open access by the U.S. Department of Agriculture: Agricultural Research Service, Lincoln, Nebraska at DigitalCommons@University of Nebraska - Lincoln. It has been accepted for inclusion in Publications from USDA-ARS / UNL Faculty by an authorized administrator of DigitalCommons@University of Nebraska - Lincoln. 


\title{
TOXICITY COMPARISON OF EIGHT REPELLENTS AGAINST FOUR SPECIES OF FEMALE MOSQUITOES
}

\author{
JULIA W. PRIDGEON, ULRICH R. BERNIER AND JAMES J. BECNEL \\ Center for Medical, Agricultural, and Veterinary Entomology, USDA-ARS, \\ 1600 SW 23rd Drive, Gainesville, FL 32608
}

\begin{abstract}
The relative toxicities of 8 repellents (DMP, Rutgers 612, DEET, IR3535, Picardin, PMD, AI3-35765, and AI3-37220) were evaluated by topical application against females of Aedes aegypti, Culex quinquefasciatus, Anopheles quadrimaculatus, and An. albimanus. Based on 24-h $\mathrm{LD}_{50}$ values, the most toxic repellent against all 4 mosquito species was AI3-37220, with values of $0.25,0.20,0.16$, and $0.11 \mu \mathrm{g} / \mathrm{mg}$ for the listed 4 mosquito species, respectively. The least toxic of the 8 repellents tested was DMP, with LD $_{50}$ values of $5.40,4.72,2.50$, and $1.83 \mu \mathrm{g} / \mathrm{mg}$, respectively. Based on the $24-\mathrm{h} \mathrm{LD}_{50}$ values, An. albimanus was the most susceptible species. The findings of the study reported herein provide a comprehensive examination of the toxicities of 4 currently used, 2 formerly used, and 2 experimental repellents against 4 mosquito species.
\end{abstract}

KEY WORDS Aedes aegypti, Culex quinquefasciatus, Anopheles quadrimaculatus, An. albimanus, repellent toxicity, topical application

\section{INTRODUCTION}

Females of the mosquito species Aedes aegypti (L.) transmit viral pathogens to humans, resulting in diseases such as yellow fever, dengue, and dengue hemorrhagic fever. These illnesses can cause severe human morbidity and mortality. The mosquito species Culex quinquefasciatus Say is a vector of the filarial parasite Wuchereria bancrofti (Cobbold) (Spirurida: Onchocercidae), which causes bancroftian filariasis in humans (Samuel et al. 2004). It is also a vector of the West Nile virus (WNV; Godsey et al. 2005), Japanese encephalitis (JE) (Nitatpattana et al. 2005), and Saint Louis encephalitis (SLE; Jones et al. 2002). Anopheles quadrimaculatus Say and An. albimanus Weidemann are anthropophilic species that are vectors involved in the transmission of the malarial parasite in humans (Richards et al. 1994).

Using repellents is a common personal protection method against mosquito bites. Since 1942, more than 40,000 compounds have been evaluated as toxicants and repellents against mosquitoes at the United States Department of Agriculture's Center for Medical, Agricultural and Veterinary Entomology (Xue et al. 2001). Some insect repellents have been reported to possess insecticidal activities against mosquitoes (Xue et al. 2003, Licciardi et al. 2006), suggesting that these compounds might also be used as toxicants for mosquito control. To compare the relative toxicities of different repellents accurately, the adult topical application bioassay was chosen to determine the relative toxicities of the following 8 compounds: 1) DMP (dimethylphthalate), a fly repellent formerly used since 1929; 2) EHD, Rutgers 612 (2-ethyl-1,3-hexanediol), 1st used in 1939; 3) DEET (N,N-diethyl-3-methylbenzamide); 4) IR3535 (3-[N-butyl-N-acetyl]-amino- propionic acid, ethyl ester), in use since the 1970s; 5) picaridin (KBR 3023, Bayrepel ${ }^{\circledR}$, 2-[2hydroxyethyl]-1-piperidinecarboxylic acid 1methylpropyl ester), in use since the 1990s; 6) PMD (para-menthane-3,8-diol), coming into commercial use since 2000; 7) AI3-35765 (1-[3cyclohexen-1-ylcarbonyl] piperidine), an experimental piperidine repellent synthesized in 1978; and 8) AI3-37220 (1-[3-cyclohexen-1-ylcarbonyl]2-methylpiperidine), another piperidine repellent synthesized in 1978. Because different susceptibility of various mosquito species to different pesticides has been previously reported (Pampiglione et al. 1985, Campos and Andrade 2003, Somboon et al. 2003, Pridgeon et al. 2008), we chose 4 mosquito species (Ae. aegypti, $C x$. quinquefasciatus, An. quadrimaculatus, and $A n$. albimanus) for our adult bioassay. Our results presented here provide important information on the relative toxicities of 2 experimental and 6 commercial repellents ( 2 were formerly used and 4 are currently used).

\section{MATERIALS AND METHODS}

\section{Mosquitoes and repellents}

All mosquitoes were reared in the insectary of the Mosquito and Fly Research Unit at the United States Department of Agriculture-Agricultural Research Service-Center for Medical, Agricultural, and Veterinary Entomology (USDA-ARS-CMAVE). We used the following 4 colony species: Ae. aegypti (Orlando, 1952), An. quadrimaculatus (Orlando, 1952), and An. albimanus (El Salvador, 1975), and Cx. quinquefasciatus (Gainesville, 1995). Only females were tested. Mosquitoes were reared in accordance with standard procedures (Reinert et al. 1997, McCall and Eaton 2001, Pridgeon et al. 2007) as 
follows: Collected eggs were hatched in a flask and larvae were held overnight in the flask and then transferred to a plastic tray containing distilled water. Larval diet was added to each tray. Mosquitoes were reared in an environmental chamber programmed with a temperature profile that represented a simulated summer day regime (ranging from $22^{\circ} \mathrm{C}$ to $30^{\circ} \mathrm{C}$ ) and $80 \%$ relative humidity (RH). Incandescent lighting was set to a crepuscular profile with a photoperiod of $14 \mathrm{~h}: 10 \mathrm{~h}$ (L:D), including $2 \mathrm{~h}$ of simulated dawn and $2 \mathrm{~h}$ of simulated dusk. Adults were held in a screened cage and provided $10 \%$ sucrose ad libitum. Bovine blood in $1 \%$ heparin contained in a pig intestine and warmed to $37^{\circ} \mathrm{C}$ was provided to adults twice a week.

The 8 repellents were either synthesized or obtained from commercial sources. The experimental repellents AI3-37565 and AI3-37220 and former repellents PMD and EHD were available as purified synthetics from the USDA-ARS Beltsville Insect Chemical Ecology Laboratory (ICEL). Picardin (KBR 3023) was provided by Lanxess (Pittsburgh, PA), IR 3535 by Merck (Darmstadt, Germany), DEET (AI3-22542-Gz) by Virginia Chemical (Portsmith, VA) and PMD by Bedoukian Research (Danbury, CT). The chemical structures of the repellents used are shown in Fig. 1.

\section{Adult bioassays and data analysis}

To determine the relative toxicity of each repellent, each chemical was serially diluted in acetone and applied topically to individual mosquitoes. Prior to application, 5-7-day-old female mosquitoes were anesthetized for $30 \mathrm{sec}$ with carbon dioxide and placed on a $4{ }^{\circ} \mathrm{C}$ chill table (BioQuip Products, Rancho Dominguez, CA). A droplet of $0.5 \mu \mathrm{l}$ of prepared repellent solution was applied to the dorsal thorax using a 700 series syringe and a PB 600 repeating dispenser (Hamilton, Reno, NV). Six concentrations providing a range of $0-100 \%$ of mortality were used on 25-30 females per concentration. Tests were replicated 3 times with a different stock population. Control treatments that consisted of $0.5 \mu 1$ of acetone delivered alone resulted in mortality rates of $<10 \%$. After treatment, mosquitoes were held in plastic cups and provided $10 \%$ sucrose solution for $24 \mathrm{~h}$ before mortality was recorded. Temperature and humidity were maintained at $26 \pm 1{ }^{\circ} \mathrm{C}$ and $80 \pm 1 \% \mathrm{RH}$, respectively. Bioassays were replicated 3 times. Correction of mortality compared to controls was performed with the use of a modified Abbott's formula (Abbott 1925). Bioassay data were pooled and probit dose response was analyzed with the use of PoloPlus probit and logit analysis software (LeOra Software, Petaluma, CA) as described previously (Pridgeon et al. 2008).
Toxicities of repellents are considered significantly different when the $95 \%$ confidence intervals of $\mathrm{LD}_{50}$ values fail to overlap $(P \leq 0.05)$.

\section{RESULTS}

Topical application bioassays of the 8 selected repellents were performed to determine the susceptibility of 4 mosquito species to each repellent. The bioassay results for Ae. aegypti are summarized in Table 1. Of the 8 repellents tested, the 2 experimental (noncommercial) repellents, AI3-37220 and AI3-35765, were the most toxic to Ae. aegypti, with $\mathrm{LD}_{50}$ values of 0.25 and $0.30 \mu \mathrm{g} / \mathrm{mg}$, respectively. The formerly used repellent, DMP, was the least toxic repellent against $A e$. aegypti, with $\mathrm{LD}_{50}$ value of $5.40 \mu \mathrm{g} /$ $\mathrm{mg}$. On the basis of $24-\mathrm{h} \mathrm{LD}_{50}$ values after topical application, the activity order of the 8 repellents as toxicants was: AI3-37220 $\geq$ AI3-35765 $>$ $\mathrm{DEET} \geq \mathrm{KBR} 3023>\mathrm{IR} 3535 \geq \mathrm{PMD}>\mathrm{EHD}$ $>$ DMP (Table 1).

To investigate whether the 8 repellents have similar toxicities against other mosquito species, topical application bioassays were performed with females of An. quadrimaculatus, An. albima$n u s$, and $C x$. quinquefasciatus. The bioassay results are presented in Tables $2-4$, respectively. Our results revealed that AI3-37220, the most toxic repellent against $A$ e. aegypti, was also the most toxic against the other 3 mosquito species, with $\mathrm{LD}_{50}$ values ranging from 0.11 to $0.20 \mu \mathrm{g} /$ $\mathrm{mg}$ (Tables 2-4). DMP, the least toxic repellent against Ae. aegypti, was also the least toxic repellent against the other 3 mosquito species with $\mathrm{LD}_{50}$ values ranging from 1.83 to $4.72 \mu \mathrm{g} /$ $\mathrm{mg}$ (Tables 2-4). However, the activity orders of the other 6 repellents as toxicants against these mosquito species differed from that of $A e$. aegypti. For An. quadrimaculatus, the activity order of the 8 repellents was: AI3-37220 $>$ DEET $\geq \mathrm{AI} 3-35765>\mathrm{KBR} 3023>\mathrm{PMD} \geq \mathrm{EHD} \geq$ IR3535 $\geq$ DMP (Table 2). The activity order against An. albimanus was: AI3-37220 > AI3$35765 \geq$ DEET $>$ KBR $3023>$ PMD $\geq$ EHD $\geq$ IR3535 $\geq$ DMP (Table 3). The activity order against $C x$. quinquefasciatus was AI3-37220 > AI3-35765 $\geq$ DEET $>>$ KBR $3023 \geq$ EHD $\geq$ PMD $>$ IR3535 > DMP (Table 4).

\section{DISCUSSION}

It has been reported that some repellents possess insecticidal activities against mosquitoes. For example, Xue et al. (2003) has reported that 16 commercial insect repellents (6 botanical and 10 synthetic organic products) in spray formulations produced significant adult knockdown (KD) and 24-h mortality against laboratoryreared female Ae. aegypti, Ae. albopictus, and An. quadrimaculatus. Furthermore, they have 
<smiles>COC(=O)c1ccccc1C(=O)OC</smiles>

DMP<smiles>CCN(CC)C(=O)c1cccc(C)c1</smiles>

DEET<smiles>CCC(C)OC(=O)N1CCCCC1CCO</smiles>

Picaridin<smiles>O=C(C1CC=CCC1)N1CCCCC1</smiles>

AI3-35765<smiles>CCCC(O)C(CC)CO</smiles>

EHD<smiles>CCCCN(CCC(=O)OCC)C(C)=O</smiles>

IR3535<smiles>CC1CCC(C(C)(C)O)C(O)C1</smiles>

PMD<smiles>CC1CCCCN1C(=O)C1CC=CCC1</smiles>

AI3-37220

Fig. 1. Chemical structures of the 8 repellents.

reported that the synthetic organic repellents induced faster KD with higher magnitude to adult mosquitoes than most botanical repellents, suggesting that repellents could also be used as toxicants for mosquito control in some situations. Consistent with their finding, our results also revealed that some insect repellents possess high insecticidal activity against mosquitoes. For 
Table 1. Toxicities of 8 repellents against female Aedes aegypti by topical application. ${ }^{1}$

\begin{tabular}{lccrcc}
\hline \hline Repellent name & $\mathrm{LD}_{50}{ }^{2}(95 \% \mathrm{CI})^{3,4}$ & $\mathrm{LD}_{95}{ }^{2}(95 \% \mathrm{CI})^{3}$ & Slope $(\mathrm{SE})$ & $\chi^{2}$ & $n$ \\
\hline IR3535 & $1.88(1.55-2.23) \mathrm{c}$ & $4.91(3.71-7.85)$ & $3.88(0.58)$ & 1.78 & 420 \\
DEET & $0.94(0.80-1.13) \mathrm{b}$ & $2.42(1.85-3.80)$ & $4.03(0.60)$ & 1.73 & 420 \\
DMP & $5.40(5.10-5.77) \mathrm{e}$ & $7.39(6.71-8.70)$ & $12.09(1.82)$ & 1.68 & 420 \\
AI3-37220 & $0.25(0.21-0.31) \mathrm{a}$ & $0.75(0.55-1.30)$ & $3.44(0.52)$ & 0.33 & 420 \\
Ethyl hexanediol & $2.88(2.64-3.08) \mathrm{d}$ & $4.41(3.96-5.31)$ & $8.88(1.44)$ & 0.45 & 420 \\
AI3-37220G & $0.31(0.26-0.37) \mathrm{a}$ & $0.77(0.60-1.15)$ & $4.13(0.61)$ & 1.96 & 420 \\
KBR 3023 & $1.09(0.92-1.30) \mathrm{b}$ & $2.49(1.94-3.91)$ & $4.60(0.77)$ & 0.35 & 420 \\
AI3-35765 & $0.30(0.25-0.35) \mathrm{a}$ & $0.63(0.50-0.94)$ & $5.10(0.85)$ & 0.68 & 420 \\
PMD & $1.90(1.59-2.21) \mathrm{c}$ & $5.90(4.41-10.22)$ & $3.35(0.57)$ & 1.18 & 420 \\
\hline
\end{tabular}

${ }^{1}$ IR 3535, 3-(N-butyl-N-acetyl)-aminopropionic acid, ethyl ester; DEET, N,N-diethyl-3-methylbenzamide; DMP, dimethylphthalate; AI3-37220, 1-(3-cyclohexen-1-ylcarbonyl)-2-methylpiperidine; AI3-37220G, AI3-37220 granular; KBR 3023, picaridin; AI335765, 1-(3-cyclohexen-1-ylcarbonyl) piperidine; PMD, para-menthane-3,8-diol.

${ }^{2} \mathrm{LD}_{50}$ and $\mathrm{LD}_{95}$ values are in units of micrograms of pesticide per milligram of mosquito.

${ }^{3} \mathrm{CI}$, confidence interval. Toxicity of repellent is considered significantly different when the $95 \% \mathrm{CI}$ fails to overlap.

${ }^{4}$ Same letters indicate that the toxicities of the repellents are not significantly different from each other because the $95 \% \mathrm{CI}$ overlapped with each other. Different letters indicate that the toxicities of the repellent are significantly different from each other because the $95 \%$ CI fails to overlap.

Table 2. Toxicities of 9 repellents against female Anopheles quadrimaculatus by topical application. ${ }^{1}$

\begin{tabular}{lccccc}
\hline \hline Repellent name & $\mathrm{LD}_{50}{ }^{2}(95 \% \mathrm{CI})^{3,4}$ & $\mathrm{LD}_{95}{ }^{2}(95 \% \mathrm{CI})^{3}$ & Slope $(\mathrm{SE})$ & $\chi^{2}$ & $n$ \\
\hline IR3535 & $2.35(2.09-2.68) \mathrm{d}$ & $5.33(4.18-8.68)$ & $4.63(0.83)$ & 1.68 & 420 \\
DEET & $0.40(0.22-0.47) \mathrm{b}$ & $1.08(0.84-2.63)$ & $3.77(1.12)$ & 0.46 & 420 \\
DMP & $2.50(1.78-5.57) \mathrm{d}$ & $19.60(8.27-279.67)$ & $1.84(0.58)$ & 0.22 & 420 \\
AI3-37220 & $0.16(0.11-0.20) \mathrm{a}$ & $0.83(0.49-3.80)$ & $2.29(0.58)$ & 0.86 & 420 \\
Ethyl hexanediol & $1.72(1.38-2.31) \mathrm{d}$ & $7.70(4.78-18.38)$ & $2.52(0.40)$ & 0.05 & 420 \\
AI3-37220G & $0.14(0.08-0.21) \mathrm{a}$ & $0.71(0.39-5.16)$ & $2.30(0.37)$ & 3.62 & 420 \\
KBR 3023 & $0.63(0.55-0.76) \mathrm{c}$ & $1.55(1.13-3.14)$ & $4.18(0.84)$ & 1.30 & 420 \\
AI3-35765 & $0.45(0.39-0.54) \mathrm{b}$ & $1.18(0.87-2.10)$ & $3.91(0.67)$ & 0.53 & 420 \\
PMD & $1.46(0.99-2.16) \mathrm{d}$ & $4.79(2.94-36.64)$ & $3.30(0.56)$ & 4.23 & 420 \\
\hline
\end{tabular}

${ }^{1}$ IR 3535, 3-(N-butyl-N-acetyl)-aminopropionic acid, ethyl ester; DEET, N,N-diethyl-3-methylbenzamide; DMP, dimethylphthalate; AI3-37220, 1-(3-cyclohexen-1-ylcarbonyl)-2-methylpiperidine; AI3-37220G, AI3-37220 granular; KBR 3023, picaridin; AI335765, 1-(3-cyclohexen-1-ylcarbonyl) piperidine; PMD, para-menthane-3,8-diol.

${ }^{2} \mathrm{LD}_{50}$ and $\mathrm{LD}_{95}$ values are in units of micrograms of pesticide per milligram of mosquito.

${ }^{3} \mathrm{CI}$, confidence interval. Toxicity of repellent is considered significantly different when the $95 \% \mathrm{CI}$ fails to overlap.

${ }^{4}$ Same letters indicate that the toxicities of the repellents are not significantly different from each other because the $95 \% \mathrm{CI}$ overlapped with each other. Different letters indicate that the toxicities of the repellent are significantly different from each other because the $95 \%$ CI fails to overlap.

Table 3. Toxicities of 9 repellents against female Anopheles albimanus by topical application. ${ }^{1}$

\begin{tabular}{llllll}
\hline \hline Repellent name & $\mathrm{LD}_{50}{ }^{2}(95 \% \mathrm{CI})^{3,4}$ & $\mathrm{LD}_{95}{ }^{2}(95 \% \mathrm{CI})^{3}$ & Slope (SE) & $\chi^{2}$ \\
\hline IR3535 & $1.67(1.34-2.18) \mathrm{d}$ & $6.63(4.30-14.89)$ & $2.75(0.46)$ & 1.22 & 420 \\
DEET & $0.22(0.17-0.27) \mathrm{b}$ & $0.76(0.50-1.93)$ & $3.00(0.63)$ & 0.60 & 420 \\
DMP & $1.83(1.52-2.24) \mathrm{d}$ & $6.52(4.59-12.17)$ & $2.98(0.46)$ & 1.23 & 420 \\
AI3-37220 & $0.11(0.09-0.13) \mathrm{b}$ & $0.30(0.23-0.48)$ & $3.55(0.51)$ & 2.92 & 420 \\
Ethyl hexanediol & $1.53(0.93-3.11) \mathrm{d}$ & $5.05(2.69-77.85)$ & $3.18(0.49)$ & 2.02 & 420 \\
AI3-37220G & $0.06(0.05-0.07) \mathrm{a}$ & $0.20(0.14-0.36)$ & $3.07(0.47)$ & 2.12 & 420 \\
KBR 3023 & $0.50(0.38-0.87) \mathrm{c}$ & $2.03(1.20-19.41)$ & $2.72(0.44)$ & 3.88 & 420 \\
AI3-35765 & $0.16(0.11-0.23) \mathrm{b}$ & $0.53(0.28-9.47)$ & $3.07(0.53)$ & 4.32 & 420 \\
PMD & $1.28(1.13-1.47) \mathrm{d}$ & $2.52(1.98-4.52)$ & $5.56(1.24)$ & 1.00 & 420 \\
\hline
\end{tabular}

${ }^{1}$ IR 3535, 3-(N-butyl-N-acetyl)-aminopropionic acid, ethyl ester; DEET, N,N-diethyl-3-methylbenzamide; DMP, dimethylphthalate; AI3-37220, 1-(3-cyclohexen-1-ylcarbonyl)-2-methylpiperidine; AI3-37220G, AI3-37220 granular; KBR 3023, picaridin; AI335765, 1-(3-cyclohexen-1-ylcarbonyl) piperidine; PMD, para-menthane-3,8-diol.

${ }^{2} \mathrm{LD}_{50}$ and $\mathrm{LD}_{95}$ values are in units of micrograms of pesticide per milligram of mosquito.

${ }^{3} \mathrm{CI}$, confidence interval. Toxicity of repellent is considered significantly different when the $95 \% \mathrm{CI}$ fails to overlap.

${ }^{4}$ Same letters indicate that the toxicities of the repellents are not significantly different from each other because the $95 \%$ CI overlapped with each other. Different letters indicate that the toxicities of the repellent are significantly different from each other because the $95 \%$ CI fails to overlap. 
Table 4. Toxicities of 9 repellents against female Culex quinquefasciatus by topical application. ${ }^{1}$

\begin{tabular}{|c|c|c|c|c|c|}
\hline Repellent name & $\mathrm{LD}_{50}{ }^{2}(95 \% \mathrm{CI})^{3,4}$ & $\mathrm{LD}_{95}{ }^{2}(95 \% \mathrm{CI})^{3}$ & Slope (SE) & $\chi^{2}$ & $n$ \\
\hline IR 3535 & $3.61(3.28-4.00) \mathrm{d}$ & $7.11(5.94-9.69)$ & $5.59(0.82)$ & 2.57 & 420 \\
\hline DEET & $0.64(0.53-0.73) b$ & $1.65(1.23-3.53)$ & $3.98(0.93)$ & 1.44 & 420 \\
\hline DMP & $4.72(4.43-5.05) \mathrm{e}$ & $7.33(6.52-8.97)$ & $8.63(1.31)$ & 2.40 & 420 \\
\hline AI3-37220 & $0.20(0.14-0.23) \mathrm{a}$ & $0.43(0.35-0.77)$ & $4.90(1.30)$ & 0.03 & 420 \\
\hline Ethyl hexanediol & $1.62(1.32-2.17) \mathrm{c}$ & $3.59(2.52-10.70)$ & $4.75(0.74)$ & 3.54 & 420 \\
\hline AI3-37220G & $0.27(0.24-0.29) \mathrm{a}$ & $0.43(0.38-0.55)$ & $8.06(1.40)$ & 0.20 & 420 \\
\hline KBR 3023 & $1.62(1.24-1.84) \mathrm{c}$ & $3.63(2.91-6.77)$ & $4.70(1.20)$ & 0.31 & 420 \\
\hline AI3-35765 & $0.48(0.43-0.53) b$ & $0.90(0.77-1.15)$ & $5.89(0.74)$ & 2.65 & 420 \\
\hline PMD & $2.14(1.94-2.35) \mathrm{c}$ & $3.46(3.02-4.48)$ & $7.92(1.39)$ & 0.01 & 420 \\
\hline
\end{tabular}

IR3535, 3-(N-butyl-N-acetyl)-aminopropionic acid, ethyl ester; DEET, N,N-diethyl-3-methylbenzamide; DMP, dimethylphthalate; AI3-37220, 1-(3-cyclohexen-1-ylcarbonyl)-2-methylpiperidine; AI3-37220G, AI3-37220 granular; KBR 3023, picaridin; AI335765, 1-(3-cyclohexen-1-ylcarbonyl) piperidine; PMD, para-menthane-3,8-diol.

${ }^{2} \mathrm{LD}_{50}$ and $\mathrm{LD}_{95}$ values are in units of micrograms of pesticide per milligram of mosquito.

${ }^{3}$ CI, confidence interval. Toxicity of repellent is considered significantly different when the $95 \%$ CI fails to overlap.

${ }^{4}$ Same letters indicate that the toxicities of the repellents are not significantly different from each other because the $95 \%$ CI overlapped with each other. Different letters indicate that the toxicities of the repellent are significantly different from each other because the $95 \%$ CI fails to overlap.

example, DEET, the most common active ingredient in commercially available insect repellent, has $\mathrm{LD}_{50}$ values of $0.94,0.40,0.22$, and $0.64 \mu \mathrm{g} /$ mg against Ae. aegypti, An. quadrimaculatus, An. albimanus, and $C x$. quinquefasciatus, respectively. The average body weight of a female Ae. aegypti, An. quadrimaculatus, An. albimanus, and $C x$. quinquefasciatus in this study was $2.85,1.92$, $1.91,2.02 \mathrm{mg}$, respectively. Therefore, the $\mathrm{LD}_{50}$ values of DEET in the unit of microgram of repellent per mosquito would be $2.69,0.76,0.41$, $1.29 \mu \mathrm{g} / \mathrm{mosquito}$. Because we used $0.5 \mu \mathrm{l}$ of solution to treat the mosquitoes topically, the $\mathrm{LD}_{50}$ values of DEET in the unit of microgram per microliter of repellent would be 5.38, 1.52, 0.82 , and $2.58 \mu \mathrm{g} / \mu 1$; i.e., $0.538 \%, 0.152 \%$, $0.082 \%$, and $0.258 \%$. The $\mathrm{LD}_{95}$ values of DEET in the unit of percentage against Ae. aegypti, An. quadrimaculatus, An. albimanus, and Cx. quinquefasciatus would be $1.378 \%, 0.414 \%, 0.145 \%$, and $0.333 \%$, respectively. Because any commercially available DEET insect repellent has a minimum percentage of active ingredient of $7.5 \%$ (up to $30 \%$ ), which is much higher than the $\mathrm{LD}_{95}$ values of DEET as described above, it is not surprising that Xue et al. (2003) found that commercially available insect repellents in spray formulations produced significant adult knockdown (KD) and 24-h mortality against adult mosquitoes. Recently, the lethal effects of 3 synthetic repellents (DEET, IR3535, and KBR3023) have been evaluated by filter paper tests to assess the knockdown effect and mortality induced by each repellent to Ae. aegypti (Licciardi et al. 2006). At the same concentration, DEET has been found to possess insecticidal activity whereas IR3535 and KBR 3023 did not (Licciardi et al. 2006). Consistent with their finding, our results also revealed that DEET had higher insecticidal activity than IR3535 and KBR3023 against all 4 mosquito species.
It has been reported that different mosquito species possess different susceptibility to different toxicants (Pampiglione et al. 1985, Campos and Andrade 2003, Somboon et al. 2003, Pridgeon et al. 2008). For example, when permethrin was topically applied to mosquitoes, the susceptibility order of 3 mosquito species was Ae. aegypti $>$ An. quadrimaculatus $>C x$. quinquefasciatus. However, when hydramethylnon was used as the toxicant, the susceptibility order of the 3 mosquito species was An. quadrimaculatus $>C x$. quinquefasciatus $>$ Ae. aegypti (Pridgeon et al. 2008). Our results in this study also revealed that different mosquitoes showed different susceptibility to different repellents. For example, when DEET or DMP was applied as the toxicant, the susceptibility order of the 4 mosquito species was An. albimanus $\geq A n$. quadrimaculatus $>C x$. quinquefasciatus $>$ Ae. aegypti (Tables 1-4). However, when IR3535 was used as a toxicant, the susceptibility order of the 4 mosquito species was changed to An. albimanus $\geq A$ e. aegypti $\geq$ An. quadrimaculatus $>C x$. quinquefasciatus. When AI3-37220 or PMD was used as a toxicant, there was no significant difference in the susceptibility among the 4 mosquito species. This could be simply due to species variability.

Although different mosquitoes showed different susceptibility to different toxicants, the relative susceptibilities were consistent for species and possibly even genera. Specifically, the comparison of $24-\mathrm{h} \mathrm{LD}_{50}$ values of the same repellent compared against the mosquito species indicated that An. albimanus was the most susceptible to all 8 repellents tested. This is quite interesting, because An. albimanus is notorious for its inability to be repelled by DEET and other repellents (McGovern and Schreck 1988, Robert et al. 1991, Klun et al. 2004), yet it is the most susceptible species to repellent toxicants. 
In summary, we evaluated the relative potency of 8 repellents as toxicants against females of 4 species of mosquitoes by topical application. The most toxic repellent was A13-37220 and the least toxic was DMP. Based on these studies, An. albimanus is the most susceptible. Our results provide important information on the toxicities of 8 repellents against 4 species of mosquito.

\section{ACKNOWLEDGMENTS}

We thank S. M. Valles and M.-Y. Choi (USDA-ARS) for critical reviews of the manuscript. We also thank Lynn Jefferson, Nathan Newlon, William Reid, Neil Sansrainte, Mathew H. Brown, Heather Furlong, and Gregory Allen (USDA-ARS) for technical support. This study was supported by a grant from the Deployed War-Fighter Protection (DWFP) Research Program funded by the US Department of Defense through the Armed Forces Pest Management Board (AFPMB). The use of trade, firm, or corporation names in this publication is for the information and convenience of the reader. Such use does not constitute an official endorsement or approval by the US Department of Agriculture or the Agricultural Research Service of any product or service to the exclusion of others that may be suitable.

\section{REFERENCES CITED}

Abbott WS. 1925. A method of computing the effectiveness of an insecticide. $J$ Econ Entomol 18:265-267.

Campos J, Andrade CF. 2003. Larval susceptibility of Aedes aegypti and Culex quinquefasciatus populations to chemical insecticides. Rev Saude Publica 37:523-527.

Godsey MS, Nasci R, Savage HM, Aspen S, King R, Powers AM, Burkhalter K, Colton L, Charnetzky D, Lasater S, Taylor V, Palmisano CT. 2005. West Nile virus-infected mosquitoes, Louisiana, 2002. Emerg Infect Dis 11:1399-1404.

Jones SC, Morris J, Hill G, Alderman M, Ratard RC. 2002. St. Louis encephalitis outbreak in Louisiana in 2001. J La State Med Soc 154:303-306.

Klun JA, Strickman D, Rowton E, Williams J, Kramer M, Roberts D, Debboun M. 2004. Comparative resistance of Anopheles albimanus and Aedes aegypti to N,N-diethyl-3-methylbenzamide (Deet) and 2methylpiperidinyl-3-cyclohexen-1-carboxamide (AI337220) in laboratory human-volunteer repellent assays. $J$ Med Entomol 41:418-422.

Licciardi S, Herve JP, Darriet F, Hougard JM, Corbel V. 2006. Lethal and behavioural effects of three synthetic repellents (DEET, IR3535 and KBR 3023) on Aedes aegypti mosquitoes in laboratory assays. Med Vet Entomol 20:288-293.

McCall PJ, Eaton G. 2001. Olfactory memory in the mosquito Culex quinquefasciatus. Med Vet Entomol 15:197-203.

McGovern TP, Schreck CE. 1988. Mosquito repellents: monocarboxylic esters of aliphatic diols. J Am Mosq Control Assoc 4:314-321.

Nitatpattana N, Apiwathnasorn C, Barbazan P, Leemingsawat S, Yoksan S, Gonzalez JP. 2005. First isolation of Japanese encephalitis from Culex quinquefasciatus in Thailand. Southeast Asian J Trop Med Public Health 36:875-878.

Pampiglione S, Majori G, Petrangeli G, Romi R. 1985. Avermectins, MK-933 and MK-936, for mosquito control. Trans R Soc Trop Med Hyg 79:797-799.

Pridgeon JW, Meepagala KM, Becnel JJ, Clark GG, Pereira RM, Linthicum KJ. 2007. Structure-activity relationships of 33 piperidines as toxicants against female adults of Aedes aegypti (Diptera: Culicidae). J Med Entomol 44:263-269.

Pridgeon JW, Pereira RM, Becnel JJ, Allan SA, Clark GG, Linthicum KJ. 2008. Susceptibility of Aedes aegypti, Culex quinquefasciatus Say, and Anopheles quadrimaculatus Say to 19 pesticides with different modes of action. J Med Entomol 45:82-87.

Reinert JF, Kaiser PE, Seawright JA. 1997. Analysis of the Anopheles (Anopheles) quadrimaculatus complex of sibling species (Diptera: Culicidae) using morphological, cytological, molecular, genetic, biochemical, and ecological techniques in an integrated approach. J Am Mosq Control Assoc 13(Suppl):1-102.

Richards FO, Flores RZ, Sexton JD, Beach RF, Mount DL, Cordon-Rosales C, Gatica M, Klein RE. 1994. Effects of permethrin-impregnated bed nets on malaria vectors of northern Guatemala. Bull Pan Am Health Organ 28:112-121.

Robert LL, Hallam JA, Seeley DC, Roberts LW, Wirtz RA. 1991. Comparative sensitivity of four Anopheles (Diptera: Culicidae) to five repellents. J Med Entomol 28:417-420.

Samuel PP, Arunachalam N, Hiriyan J, Thenmozhi V, Gajanana A, Satyanarayana K. 2004. Host-feeding pattern of Culex quinquefasciatus Say and Mansonia annulifera (Theobald) (Diptera: Culicidae), the major vectors of filariasis in a rural area of south India. $J$ Med Entomol 41:442-446.

Somboon P, Prapanthadara LA, Suwonkerd W. 2003. Insecticide susceptibility tests of Anopheles minimus s.1., Aedes aegypti, Aedes albopictus, and Culex quinquefasciatus in northern Thailand. Southeast Asian J Trop Med Public Health 34:87-93.

Xue RD, Barnard DR, Ali A. 2001. Laboratory and field evaluation of insect repellents as oviposition deterrents against the mosquito Aedes albopictus. Med Vet Entomol 15:126-131.

Xue RD, Ali A, Barnard DR. 2003. Laboratory evaluation of toxicity of 16 insect repellents in aerosol sprays to adult mosquitoes. J Am Mosq Control Assoc 19:271-274. 